\title{
REESTRUTURANDO O TRABALHO NO BLOCO CIRÚRGICO COM A PANDEMIA DA COVID-19
}

https://doi.org/10.5327/Z1414-4425202100010001

A

pandemia da coronavirus disease (Covid-19) foi declarada pela Organização Mundial da Saúde $(\mathrm{OMS})^{1}$, e o governo público estabeleceu medidas de prevenção e controle da doença, recomendando o cancelamento provisório de procedimentos cirúrgicos eletivos. Excetuando-se cirurgias emergenciais e de urgência, que não mudaram suas indicações, um vasto número de cirurgias foi adiado por todo o país.

Os sistemas de saúde (SS) em todo o mundo estão sendo desafiados como nunca antes visto. Após a primeira onda dessa pandemia, o volume de pacientes com necessidades de tratamento cirúrgico é crítico, e os hospitais e profissionais de saúde devem estar preparados para atender a essa demanda ${ }^{2}$. Haverá novamente o risco de colapso dos SS pela concomitância de tratamentos postergados e novos pacientes acometidos pela Covid-19.

Em termos globais, a rigorosa adesão aos protocolos de cuidados de saúde governamentais visa promover o retorno das atividades cirúrgicas com certo grau de normalidade, primordialmente objetivando a redução de custos socioeconômicos. A forma de aplicar e utilizar esse conjunto de ações deve ser adaptada de acordo com as determinações governamentais, os recursos locais e os dados epidemiológicos locorregionais da presença e da carga da doença ${ }^{3}$.

As receitas dos hospitais privados apresentaram queda significativa em 2020, segundo dados da Associação Nacional de Hospitais Privados, que apontam que a redução nos quatro primeiros meses de 2020, em comparação ao mesmo período de 2019 , foi de $26 \%$, com importante atrelamento entre as despesas variáveis e a manutenção das despesas fixas ${ }^{4}$.

Com o adiamento das cirurgias, houve o represamento de casos e o aumento das complicações ${ }^{5,6}$. Em meados de abril e em maio de 2020, foram publicadas algumas orientações para retomada gradual dos procedimentos cirúrgicos eletivos, baseando-se em protocolos de segurança e fluxos exclusivos e segregados dentro da unidade de saúde, nomeadas de fluxo Covid Free.

O desafio era como garantir que o paciente saísse do isolamento, viesse ao hospital realizar o procedimento cirúrgico e retornasse em segurança, sem ser contaminado. Foram tomadas medidas como: leitos exclusivos e isolados para internação e terapia intensiva, elevadores exclusivos, reforço da higiene dos ambientes, testagem do paciente pelo método swab nasal PCR SARS-CoV2 em de 48 a 72 horas antes do procedimento, aplicação de termo de consentimento específico, internação direta no leito (sem passagem pela recepção), triagem com aferição de temperatura e questionário de sintomas nas últimas 24 horas de todos os colaboradores, médicos e terceiros que acessam o hospital, bloqueio de visitantes, uso de máscara cirúrgica descartável no paciente, uso de máscara N95 pela equipe assistencial envolvida no ato cirúrgico, uso de filtro nas cirurgias videolaparoscópicas por risco de dispersão de aerossóis na dispersão do gás carbônico utilizado no pneumoperitônio ${ }^{7,8}$.

Outros desafios foram surgindo na implementação da retomada, como alta demanda dos laboratórios para realização do PCR, provocando atrasos na liberação dos resultados e adiamento dos procedimentos, aumento do absenteísmo dos colaboradores por contaminação externa, regressão de fase do plano do estado, com novas restrições e medidas de isolamento, causando medo e insegurança nos pacientes em ir para o hospital.

A chegada da vacina trouxe esperança e aumento da expectativa de retorno às atividades normais.

As vacinas para a imunização contra o SARS-CoV-2 possuem papel fundamental para um novo momento de maior segurança e progressão de atividades para o cenário econômico. Não obstante essa perspectiva, os procedimentos cirúrgicos eletivos podem gradativamente encaminhar-se para números habituais do cenário pré-pandemia.

Além de fluxos predefinidos na fase de avaliação pré-operatória, como exames de RT-PCR, no momento em que se iniciou o calendário vacinal no país, a avaliação sobre possíveis efeitos colaterais após a aplicação do imunizante também deverá ser contemplada.

Tendo em vista o cenário com as vacinas, torna-se imprescindível a sistematização nos fluxos pré-operatórios para verificar a administração das doses correspondentes a cada 
vacina, período possível para identificação de efeitos adversos, bem como o tempo de garantia de imunidade depois da administração das doses complementares.

Cada indivíduo tem particularidades em relação às reações à vacina, a depender de fatores como idade e situação imunológica. De modo geral, após a administração da segunda dose, a imunização acontece depois de 14 dias, pois esse é o tempo que nosso sistema leva para criar anticorpos neutralizantes, que barram a entrada do vírus nas células 9 .

O indicador de absenteísmo da enfermagem é um dado de alta relevância para qualquer organização de saúde, para análises tanto de causas quanto de efeitos impactantes à assistência ao paciente. Um estudo de 2019 revelou que a média de absenteísmo em empresas brasileiras varia entre 3 e 4\%, sendo essas taxas aceitáveis em uma organização de trabalho.

No país, ainda no cenário pandêmico da Covid-19, os números de afastamento dos profissionais de enfermagem ainda são imensuráveis. Os serviços de saúde têm o desafio de trabalhar suas escalas assistenciais de forma a atender às necessidades dos pacientes, mesmo com aumento das taxas de absenteísmo. Além da contaminação pelo vírus SarsCoV-2, há o forte impacto da síndrome de burnout, o estresse pelas políticas governamentais e institucionais, bem como as condutas da sociedade no que se refere às medidas preventivas contra o vírus, os dilemas éticos para execução de procedimentos, os transtornos de ansiedade, os transtornos depressivos, a automedicação aumentada, o cansaço, a insegurança e o medo de contaminar seus familiares ${ }^{10}$.

Por fim, é um grande desafio por parte das organizações ser sustentável, para permear sua perenidade, de modo que os custos sejam nutridos da melhor forma por suas receitas, e, ainda assim, manter um modelo competitivo com qualidade da assistência e segurança para pacientes e colaboradores.

Marcia Hitomi Takeiti (1)

Mestre em Enfermagem Profissional pelo Centro Universitário São Camilo. Coordenadora do Centro de Material e Esterilização do Instituto do Coração InCor, do Hospital das Clínicas da Universidade de São Paulo, São Paulo, Brasil.

Ricardo Cezar de Oliveira (1) MBA em Gestão Estratégica em Saúde. Coordenador do Centro Cirúrgico e do Centro de Material de Esterilização do Hospital São Camilo Santana, São Paulo, Brasil.

\section{André Cordeiro da Santa Cruz (1)}

Especialista em Centro Cirúrgico pelo Programa de Aprimoramento Profissional do Hospital das Clínicas da Faculdade de Medicina da Universidade de São Paulo e em Informática em Saúde pela Universidade Federal de São Paulo. Coordenador do Centro Cirúrgico do Hospital Beneficência Portuguesa, São Paulo, Brasil.

\section{REFERÊNCIAS}

1. World Health Organization. Clinical management of severe acute respiratory infection when COVID-19 is suspected. COVID-19: clinical care [Internet]. World Health Organization; 2020 [acessado em 20 fev. 2021]. Disponível em: https://www.who.int/publications/i/item/ WHO-2019-nCoV-clinical-2021-1

2. Cimerman S, Chebabo A, Cunha CA, Rodríguez-Morales AJ. Deep impact of COVID-19 in the healthcare of Latin America: the case of Brazil. Braz J Infect Dis. 2020;24(2):93-5. https://doi.org/10.1016/j. bjid.2020.04.005

3. Brasil. Ministério da Saúde. DATASUS. TabNet Win32 3.0: Mortalidade - Brasil. Brasil: Ministério da Saúde [acessado em 18 fev. 2021]. Disponível em: http://tabnet.datasus.gov.br/cgi/tabcgi.exe?sim/cnv/ obt10uf.def

4. Ferreira MA. Observatório ANAHP 2020 [Internet]. São Paulo; 2020 [acessado em 17 jan. 2021]. Disponível em: https://setorsaude.com. br/anahp-lanca-observatorio-2020-e-apresenta-dados-do-forteimpacto-da-covid-19-no-setor-hospitalar/

5. Colégio Brasileiro de Cirurgiões. Orientações para o retorno de cirurgias eletivas durante a pandemia de COVID-19 [Internet]. Brasil: Colégio Brasileiro de Cirurgiões; 2020 [acessado em 23 jan. 2021]. Disponível em: https://cbc.org.br/wp-content/ uploads/2020/05/PROPOSTA-DE-RETOMADA-DAS-CIRURGIASELETIVAS-30.04.2020-REVISTO-CBCAMIBSBASBOT-ABIH-SBI-EDEMAIS.pdf

6. American Society of Anesthesiologists. Joint Statement: Roadmap for Resuming Elective Surgery after COVID-19 Pandemic [Internet]. American Society of Anesthesiologists; 2020 [acessado em 23 jan. 2021]. Disponível em: https://www. asahq.org/about-asa/newsroom/news-releases/2020/04/ joint-statement-on-elective-surgery-after-covid-19pandemic 
7. Colégio Brasileiro de Cirurgiões. Recomendações do Colégio Brasileiro de Cirurgiões para cirurgia videolaparoscópica em pacientes com suspeita de infecção por COVID-19 [Internet]. Colégio Brasileiro de Cirurgiões; 2020 [acessado em 23 jan. 2021]. Disponivel em: https:// cbc.org.br/wp-content/uploads/2020/04/Laparoscopia.pdf

8. Rocha LP, Castanheira JS, Barlem ELD, Carvalho DP, Gutierres ED, Pasos CM, et al. Paciente cirúrgico no contexto da pandemia de COVID-19 [Internet]. Rio Grande: Universidade Federal do Rio Grande, Escola de Enfermagem; 2020 [acessado em 23 jan. 2021]. Disponível em: https://eenf.furg.br/images/COVID/Paciente_Cirurgico_no_ Contexto_da_Pandemia_de_COVID-19.pdf
9. Instituto Butantan. Quanto tempo demora para adquirir imunidade após tomar a vacina contra a COVID-19 [Internet]. Instituto Butantan; 3 fev. 2021 [acessado em 7 fev. 2021]. Disponível em: https://butantan. gov.br/noticias/quanto-tempo-demora-para-adquirir-imunidadeapos-tomar-a-vacina-contra-a-covid-19

10. Souza e Souza LPS, Souza AG. Enfermagem brasileira na linha de frente contra o novo coronavírus: quem cuidará de quem cuida? J Nurs Health [Internet]. 2020 [acessado em 7 fev. 2021];10(n. esp.):e20104005. Disponivel em: https://docs.bvsalud.org/biblioref/2020/05/1095606/1enfermagem-brasileira-na-linha-de-frente-contra-o-novo-coron ygPksqt.pdf 